\title{
Editorial
}

\section{Marching On}

Thalassa Cruso, a gardener and television host once known as "the Julia Child of horticulture," is widely reported to have described March as "a month of considerable frustration," but it is also a month of considerable excitement this year for College $\mathcal{E}$ Research Libraries. ${ }^{1}$

In this "regular" issue of the journal, we include essays on distinctive collections, information literacy instruction and assessment, demanddriven acquisitions, library leadership during disaster response, and the culture of assessment in academic libraries. In addition to the range of topics included, this issue is notable for the ways in which our transition to digital-only publication can be seen in the scholarly communications process. For example, we have taken advantage of the elimination of page count limitations to bring new scholarship to our readers more quickly. While the time between acceptance and publication in CERL once ranged between 16-20 months, there are articles appearing in this month's issue less than 12 months from their date of acceptance. Likewise, our enhancements to the $C E R L$ Web site and our increased use of social media have allowed more of our readers to discover and make use of our pre-prints even before those articles appear in the journal. Farkas, Hinchliffe, and Houk's "Bridges and Barriers: Factors Influencing a Culture of Assessment in Academic Libraries," for example, is appearing for the first time in its final form in this issue, but it has already been accessed 3,373 times (and counting) as a pre-print. While interest in this article may have been driven, in part, by our decision to host a CERL Online Forum with the authors in April 2014, we see robust use of all $C \mathcal{E} R L$ pre-prints in the months between acceptance and publication. We expect this trend to only grow in the future.

Another benefit of our digital publication strategy is our new ability to plan and produce "special" issues without any impact on the journal's regular publication schedule. Also this month, we are releasing a special issue commemorating the $75^{\text {th }}$ anniversary of the Association of College \& Research Libraries (and of CERL). This issue, available through the CERL Web site, includes the seven "landmark essays" that readers selected from a list of 30 articles compiled by members of the CERL editorial board (with assistance from former CERL editors), as well as new essays reflecting on the enduring value of those articles for research and practice in academic librarianship. The issue concludes with an eye to the future provided by Ithaka S\&R's Roger C. Schonfeld, who challenges us to think about the place of the society-sponsored journal in an evolving scholarly communications market. We will continue to take advantage of the opportunity to highlight ACRL initiatives and programs with a research focus in future special issues, including one scheduled for publication in March 2016 on the Assessment in Action program (http://www.ala.org/acrl/AiA).

And our future is also very much the focus of our final offering for this "month of considerable excitement" as we invite CERL authors, editorial board members, and colleagues to present their thoughts at a Research Forum at ACRL 2015 in Portland. "Putting the 'Research' in the Association of College \& Research Libraries" will invite participants to consider the role that a professional society such as ACRL plays in the promotion, dissemination, and application of rigorous research to the design, delivery, and assessment of our work as librarians, archivists, curators, and other information professionals. 


\section{Notes}

1. Margalit Fox, "Thalassa Cruso, 88, Plant Lover Who Shared Her Passion on TV," The New York Times, June 18, 1997, http://www.nytimes.com/1997/06/18/arts/thalassa-cruso-88-plant-loverwho-shared-her-passion-on-tv.html 